\title{
Caracterização morfoanatômica das folhas de Eremanthus erythropappus (DC.) MacLeisch, Asteraceae
}

\author{
Rafael C. Dutra, ${ }^{* 1,2}$ Sávio O. Ferraz, ${ }^{2}$ Daniel S. Pimenta, ${ }^{3}$ Orlando V. Sousa ${ }^{2}$
}

\author{
${ }^{1}$ Departamento de Farmacologia, Campus Universitário, Trindade, Bloco D/CCD, Universidade Federal de Santa \\ Catarina, Caixa Postal 476, 88049-900, Florianópolis, SC, Brasil, \\ ${ }^{2}$ Departamento Farmacêutico, Faculdade de Farmácia e Bioquímica, Campus Universitário, Universidade Federal \\ de Juiz de Fora, 36036-900 Juiz de Fora, MG, Brasil, \\ ${ }^{3}$ Departamento de Botânica, Instituto de Ciências Biológicas, Universidade Federal de Juiz de Fora, Rua José \\ Lourenço Kelmer s/n, Campus Universitário, Bairro São Pedro, 36036-900 Juiz de Fora, MG, Brasil.
}

\begin{abstract}
RESUMO: Eremanthus erythropappus (DC.) MacLeisch (Asteraceae), popularmente conhecida como "candeia-da-serra", é uma espécie utilizada na medicina tradicional como cicatrizante e antimicrobiano. O objetivo do presente trabalho foi comparar o número de tricomas glandulares nas folhas jovens e adultas de E. erythropappus, assim como realizar a caracterização morfoanatômica destas folhas. Secções transversais e paradérmicas das folhas foram submetidas às microtécnicas fotônicas e à microscopia eletrônica de varredura. A quantificação dos tricomas glandulares foi realizada em folhas jovens e adultas com auxílio de câmara clara. As folhas são alternas ou fasciculadas e a lâmina foliar possui epiderme uniestratificada, revestida por cutícula delgada e lisa e mesofilo dorsiventral. Em ambas as faces da epiderme, ocorrem estômatos predominantemente anomocíticos e tricomas glandulares inseridos em depressões. $\mathrm{Na}$ face abaxial observam-se numerosos tricomas tectores. O parênquima paliçádico é uniestratificado e o parênquima voltado para a face abaxial é formado por três a cinco camadas de células com disposição compacta. As folhas

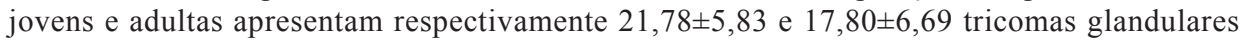
na face adaxial. A análise morfoanatômica das folhas de E. erythropappus mostra-se um método rápido e prático para a identificação e controle de qualidade de espécies vegetais utilizadas na terapêutica.
\end{abstract}

Unitermos: Eremanthus erythropappus, Asteraceae, morfoanatomia.

\begin{abstract}
Leaf morpho-anatomical characterization of Eremanthus erythropappus (DC.) MacLeisch, Asteraceae". Eremanthus erythropappus (DC.) MacLeisch (Asteraceae), commonly known as 'candeia-da-serra', is a plant used in folk medicine as wound healing and antimicrobial. The aim of this study was to compare the number of glandular trichomes between the young and the mature leaves, as well as to perform the morpho-anatomical characterization of E. erythropappus leaves. Transverse and paradermal sections of the leaves were prepared according to light and scanning microtechniques for the morpho-anatomical characterization. The quantification of glandular trichomes on the adaxial surface of the epidermis was evaluated in young and mature leaves with camera lucida. The leaves are alternate or fasciculate and the blade has uniseriate epidermis coated with thin and smooth cuticle and dorsiventral mesophyll. There are predominantly anomocytic stomata on both surfaces, as well as glandular trichomes located in epidermal depressions. Various nonglandular trichomes are encountered on the abaxial surface. The palisade parenchyma consists of a single layer of cells and the parenchyma which is faced to the abaxial surface comprehends three to five layers of cells in compact arrangement. The young and mature leaves showed, respectively, $21.78 \pm 5.83$ e $17.80 \pm 6.69$ glandular trichomes on the adaxial side. The morphoanatomical analysis of E. erythropappus leaves has proved to be a practical and rapid method for the identification and quality control of the vegetal species used for medical purposes.
\end{abstract}

Keywords: Eremanthus erythropappus, Asteraceae, morpho-anatomy. 


\section{INTRODUÇÃO}

A família Asteraceae possui cerca de 1000 gêneros e 25000 espécies cosmopolitas, sendo encontradas em regiões tropicais, subtropicais e temperadas (Lorenzi \& Matos, 2002). Muitas espécies desta família são conhecidas por possuírem estruturas secretoras nas folhas, como tricomas, que secretam óleos essenciais e outros metabólitos secundários (Aguilera et al., 2004; Gregio \& Moscheta, 2006; Fonseca et al., 2006; DelVechio-Vieira et al., 2008). Além disso, são fontes de produtos naturais bioativos com potencial farmacológico (Lorenzi \& Matos, 2002).

Eremanthus erythropappus (DC.) MacLeisch, sinonimizada de Vanillosmopsis erythropappa SchultzBip, pertencente à família Asteraceae e conhecida popularmente como "candeia-da-serra" (Sousa et al., 2003), é encontrada na Argentina, norte e leste do Paraguai e no Brasil (Carvalho, 1994). No Brasil predomina nos Estados das regiões Sudeste, Sul e Centro-Oeste (Carvalho, 1994; Pedralli et al., 1997). É uma espécie arbórea, reconhecida pelas inflorescências com capítulos róseos, e cresce geralmente em solos rasos e pobres (Silvério, 2004). As folhas são simples, alternas e aveludadas com características de dupla coloração (parte superior verde e parte inferior branca e tomentosa) (Corrêa, 1931; Chaves \& Ramalho, 1996).

$\mathrm{Na}$ medicina popular, E. erythropappus é utilizada como cicatrizante e no combate a infecções (Cruz, 1995; Silvério, 2004). O óleo essencial obtido da madeira, rico em $\alpha$-bisabolol, apresenta atividade antibacteriana, antimicótica (Bolmann et al., 1981), antiulcerogênica (Gottlieb \& Kubitzki, 1983), antiflogística e espasmódica (Pérez, 2001; Scolforo et al., 2002). O óleo essencial das folhas contém $\beta$-pineno, $\beta$-cariofileno, $\beta$-mirceno e germacreno $\mathrm{D}$ como componentes majoritários e possui atividades antimicrobiana, antinociceptiva e anti-inflamatória (Sousa et al., 2008a; Sousa et al., 2008b). O extrato etanólico das folhas de E. erythropappus apresenta efeitos antinociceptivo, anti-inflamatório e antiulcerogênico (Silvério et al., 2008).

Estudos fitoquímicos têm identificado constituintes sesquiterpenoídicos, como $\alpha$-bisabolol (Gottlieb \& Magalhães, 1958), costunolídeo e eremantina (Baker et al., 1972), vanilosmina (Corbrella et al., 1974) e 15-desoxigoyazensolídeo (Vichnewski et al., 1976) em E. erythropappus. Outros sesquiterpenoides e lactonas sesquiterpenoídicas também foram identificados na espécie (Braun et al., 2003; Sousa et al., 2008a; Sousa et al., 2008b).

Recentemente, Sousa et al. (2008b) demonstraram alteração na composição química e na atividade antimicrobiana dos óleos essenciais obtidos das folhas jovens e adultas de E. erythropappus, o que pode ser decorrente do envelhecimento das células e dos tecidos foliares, alterando o metabolismo da planta. Baseado neste estudo e na importância química e farmacológica, o presente trabalho teve como objetivo realizar a caracterização morfoanatômica, assim como quantificar o número de tricomas glandulares nas folhas jovens e adultas de E. erythropappus.

\section{MATERIAL E MÉTODOS}

O material vegetal de Eremanthus erythropappus (DC.) MacLeisch foi coletado em junho de 2004, no Campus Universitário da Universidade Federal de Juiz de Fora e identificado pela Dra. Fátima Regina Gonçalves Salimena do Departamento de Botânica, UFJF, Brasil. Uma exsicata da espécie foi depositada no Herbário CESJ da Universidade Federal de Juiz de Fora/MGBrasil sob o número 25.363. A coleta constou de folhas jovens e adultas de quinze indivíduos distintos, utilizadas para caracterização morfoanatômica e quantificação dos tricomas glandulares na face adaxial. As folhas jovens e maduras foram diferenciadas com base na posição caulinar, no comprimento e na coloração das folhas: folhas jovens, coletadas na porção do primeiro nó, com 4-5 cm e coloração verde-claro; folhas maduras, obtidas na região do quinto nó, com 7-9 cm de comprimento e coloração verde-escura.

A descrição macroscópica foi realizada à vista desarmada e com auxílio de lupa estereoscópica, para a observação de detalhes morfológicos. Avaliaramse as dimensões das folhas com auxílio de paquímetro manual.

Para a descrição microscópica realizaram-se secções das folhas in natura, logo após a colheita, à mão livre, com auxílio de uma lâmina e suporte. Efetuaramse secções transversais e paradérmicas no nível do terço médio inferior na região mediana e do bordo foliar. Os cortes foram lavados com água destilada, selecionados e clareados com solução de hipoclorito de sódio a $20 \%$, até a obtenção de contraste satisfatório entre as células epidérmicas comuns e os tricomas glandulares, novamente lavados, corados com azul de astra/fucsina básica (Roeser, 1972) ou Sudam III (Sass, 1951) e montados sobre lâminas com auxílio de gelatina glicerinada. As folhas clarificadas foram submetidas à contagem do número de tricomas glandulares na face adaxial, observando-se a região mediana e intercostal com auxílio de câmara clara. Quatro campos microscópicos aleatórios/folha foram obtidos e com o valor médio foi realizada uma análise comparativa entre quinze indivíduos distintos. Os resultados foram expressos como média \pm desvio padrão. Para avaliar a significância das diferenças entre as médias dos resultados obtidos foi aplicado o teste t de Student, com auxílio do software Statistical GraphPad Prisma 4.0 (GraphPad Software, Inc.). Foi estabelecido como limite de significância $p<0,05$. A análise estrutural das lâminas histológicas foi realizada em microscopia de luz, com as 
imagens capturadas por uma câmara de vídeo acoplada ao microscópio (BX451, Olympus - Japão), digitalizadas e analisadas por meio do software Image-Proplus (Media Cybernetics).

A análise ultraestrutural das faces adaxial e abaxial da epiderme (microscopia eletrônica de varredura - MEV) foi feita em lâmina foliar fresca, com ausência de metalização do material vegetal. As eletromicrografias foram realizadas no microscópio eletrônico de varredura com pressão variável (LEO 435VP, MEVPV) no Laboratório de Patologia, Instituto Oswaldo Cruz/ Fiocruz-RJ.

\section{RESULTADOS E DISCUSSÃO}

Eremanthus erythropappus apresenta folhas alternas ou fasciculadas, papiráceas a coriáceas, inteiras, oblongo-elípticas a ovaladas, de ápice obtuso ou acuminado, base obtusa, margem inteira e pecíolo de 0,5 a $1,0 \mathrm{~cm}$ de comprimento com 0,3 a $0,5 \mathrm{~cm}$ de diâmetro. Lâmina de 8 a $15 \mathrm{~cm}$ de comprimento por 5 a 8 $\mathrm{cm}$ de largura, discolor, face adaxial de coloração verdepálido e a abaxial verde-esbranquiçado. Venação do tipo camptódroma-broquidódroma (Figura 1).
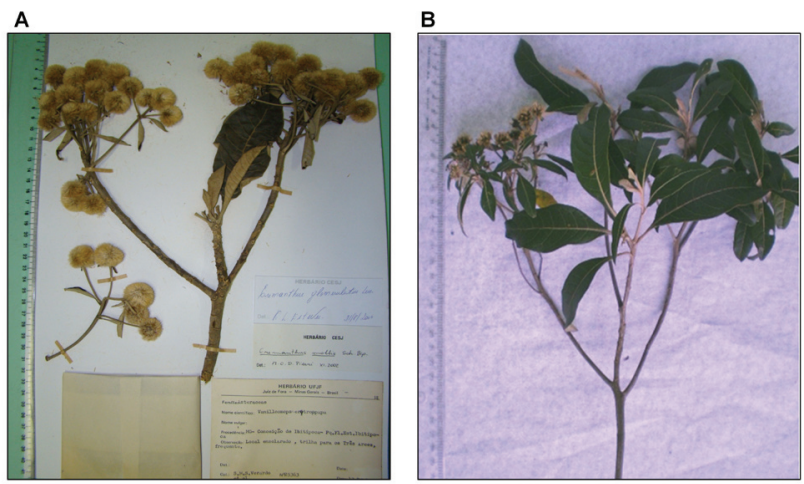

Figura 1. Aspecto morfológico de Eremanthus erythropappus. Detalhes das folhas e das inflorescências. (A) Exsicata depositada no Herbário CESJ da UFJF/MG-Brasil sob o número 25.363. B. Aspecto geral de exemplar obtido no campus da UFJF. Ramo florido.

A lâmina foliar possui epiderme unisseriada, com paredes anticlinais ligeiramente onduladas em vista frontal. A cutícula é delgada e lisa (Figura 2A). A folha é dorsiventral e anfiestomática, com pequeno número de estômatos adaxiais. Foram observados estômatos anomocíticos e alguns anisocíticos, que se localizam no mesmo nível das demais células epidérmicas (Figura $2 \mathrm{~A}$ e B). Em ambas as faces epidérmicas da lâmina foliar foram observados tricomas glandulares, que apresentam pedúnculo unicelular e, na face adaxial, encontram-se em depressões epidérmicas. A glândula é capitada e unicelular, com armazenamento de óleo intracelular, verificado com auxílio de reação com
Sudan III, sendo os constituintes mais oxidados na face adaxial, verificado na clarificação com hipoclorito de sódio (Figura 2E). Na face abaxial foram observados tricomas tectores do tipo ramificado em profusão, o que justifica o aspecto esbranquiçado das folhas a olho nu devido à reflexão da luz. Estes tricomas possuem base bicelular unisseriada e ramificações aladas apicais (Figura 2C e D). A célula da base do pedúnculo tem parede reforçada com lignificação (Figura 2D).

De acordo com Metcalfe e Chalk (1950), os estômatos podem ser anomocíticos e anisocíticos na família Asteraceae, com predominância do primeiro tipo, e podem ocorrer em ambas as faces da epiderme, como observado nas folhas de E. erythropappus. Segundo Parkhust (1978) e Mott et al. (1982), a característica anfiestomática pode representar um meio de aumentar a taxa fotossintética, por permitir uma troca gasosa eficiente se comparada com folhas hipoestomáticas. Em condições xéricas, a folha necessita aproveitar o tempo limitado de alta umidade relativa para realizar as trocas gasosas, o que poderá ser mais eficiente quanto maior for a área estomática útil (Medri \& Lleras, 1980). Em plantas de cerrado é muito comum a presença de estômatos nas duas faces da lâmina foliar (Morretes, 1969), como observado para as folhas de $E$. erythropappus.

Os tricomas são estruturas importantes na adaptação em ambientes xéricos, pois mantêm uma atmosfera saturada em vapor de água em torno da folha (Fahn \& Cutler, 1992; Larcher, 2000). Além desse efeito direto reduzindo a transpiração, estas estruturas podem também influenciar indiretamente a economia de água das plantas através da regulação da temperatura pela reflexão da radiação solar que chega até as folhas (Salatino et al., 1986; Larcher, 2000). Assim, os tricomas podem representar uma adaptação morfológica que favorece a manutenção da assimilação de dióxido de carbono $\left(\mathrm{CO}_{2}\right)$, pois promovem a redução da temperatura foliar em períodos de elevada temperatura ambiental e baixa disponibilidade de água (Ehleringer \& Mooney, 1978). Foram encontrados tricomas tectores nas folhas de E. erythropappus e tricomas similares também foram descritos para outras espécies de Asteraceae (Rodrigues et al., 1996; Oliveira et al., 2000; Tavares et al., 2000; Del-Vechio-Vieira et al., 2008). Tricomas glandulares capitados foram encontrados nas folhas de E. erythropappus, assim como em outras espécies de Asteraceae (Oliveira et al., 2000). A associação de tricomas tectores, diminuindo a perda de umidade na face com maior índice estomático, com tricomas glandulares que secretam substâncias lipofílicas, cria um microambiente hidrofóbico que protege ainda mais a folha de dessecações por estresse hídrico, também verificado em outras xerófitas (Fahn \& Cutler, 1992). No desenvolvimento relativamente lento da candeia-da-serra em ambientes rupestres ou 
de cerrado verifica-se a manutenção das folhas na planta, não apresentando aspecto caducifólio (Pérez, 2001; Galdino et al., 2006). A presença dos tricomas, tanto tectores, quanto glandulares é, portanto, fator fundamental para manutenção das folhas na planta e a adaptação da espécie nesses ambientes pobres em recursos no substrato. A defesa química, neste caso providenciado pelo óleo essencial, provê, além dessa defesa a fatores abióticos, a possibilidade de defesa à herbivoria (Fahn \& Cutler, 1992; Harborne, 1993), o que também justifica a manutenção dessa espécie nesses locais com poucas opções para os herbívoros ali presentes, já que muitas vezes são observadas em candeais (matas homogêneas) (Scolforo et al., 2004).

O mesofilo das folhas de E. erythropappus é dorsiventral, com parênquima paliçádico formado por uma camada de células longas e estreitas e parênquima compacto formado por três a cinco camadas de células poliédricas (Figura 2A-C). A presença de poucos espaços intercelulares no mesofilo é um aspecto típico de plantas xeromórficas, onde a diminuição de apoplasto dificulta a dissipação do vapor d'água, conferindo uma melhor adaptação das espécies (Fahn, 1978; Fahn \& Cutler, 1992).
A Figura 3 apresenta a quantificação dos tricomas glandulares presentes nas folhas jovens eadultas de E. erythropappus, as quais possuem respectivamente $21,78 \pm 5,83$ e $17,80 \pm 6,69$ tricomas glandulares na face adaxial. As folhas jovens apresentaram um aumento significante no número de tricomas glandulares quando comparados com as folhas adultas. Estes resultados estão de acordo com Sousa et al. (2008a) que verificaram um maior rendimento na extração do óleo essencial das folhas jovens $(0,45 \%)$ em comparação com as folhas adultas $(0,25 \%)$, indicando que as folhas jovens produzem uma maior quantidade de óleos voláteis ou possuem mecanismos de armazenamento que impedem a volatilização dos constituintes. Além disso, este mesmo estudo demonstrou diferenças na composição química dos óleos essenciais e na atividade antimicrobiana das folhas jovens e adultas obtidas de E. erythropappus. Através da análise ultraestrutural das folhas de E. erythropappus (microscopia eletrônica de varredura - MEV), foi possível observar o elevado número de tricomas glandulares na face adaxial, assim como a distribuição dos tricomas tectores presentes na face abaxial da epiderme (Figura 4).
A

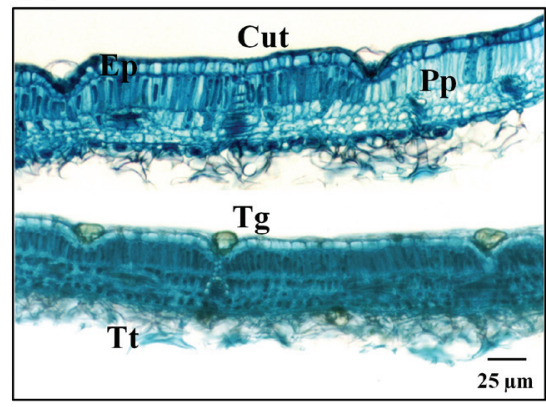

D

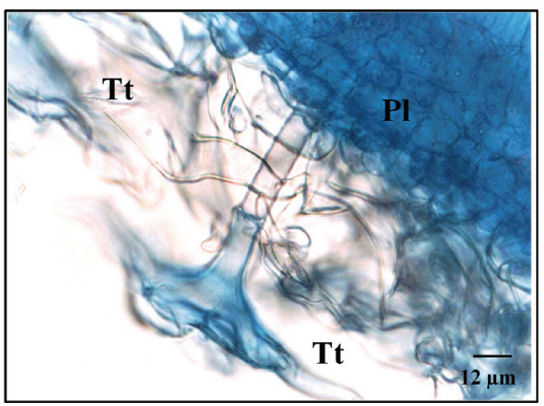

B

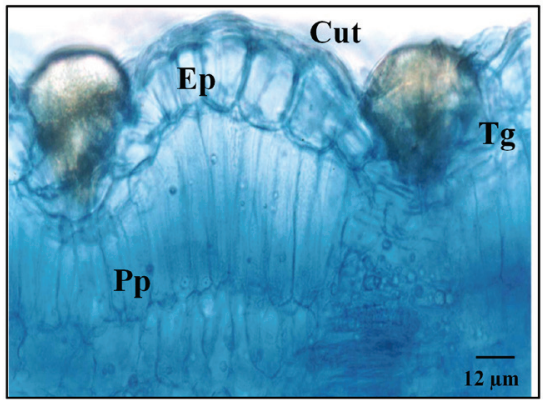

C

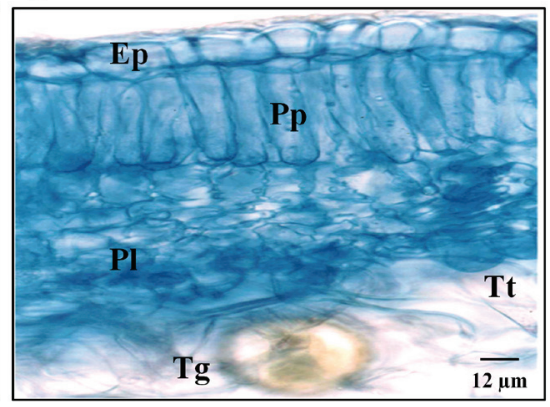

E

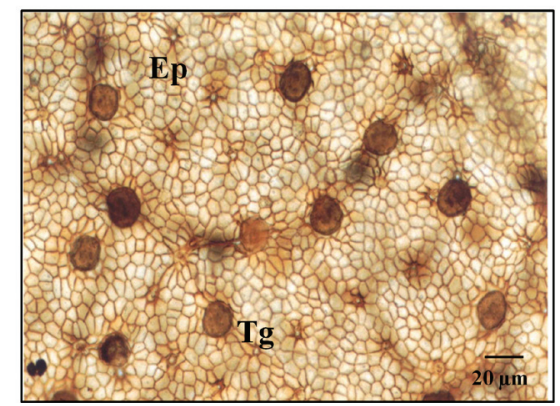

Figura 2 A-E. Caracterização anatômica de folhas de Eremanthus erythropappus. A. Secção transversal do mesofilo mostrando organização dorsiventral. Presença de tricomas glandulares e tectores. Parênquima paliçádico uniestratificado e parênquima compacto formado por três a cinco camadas de células. B-D. Lâmina foliar evidenciando mesofilo dorsiventral, epiderme uniestratificada revestida por cutícula delgada e lisa. Presença de tricomas glandulares nas faces adaxial e abaxial. Tricomas tectores presentes na face epidérmica abaxial. E. Teste histoquímico positivo para substâncias lipofílicas evidenciado por Sudam III. Cut: cutícula; Ep: epiderme; Pp: parênquima paliçádico; Pl: parênquima lacunoso; Tg: tricoma glandular; Tt: tricoma tector. 
A

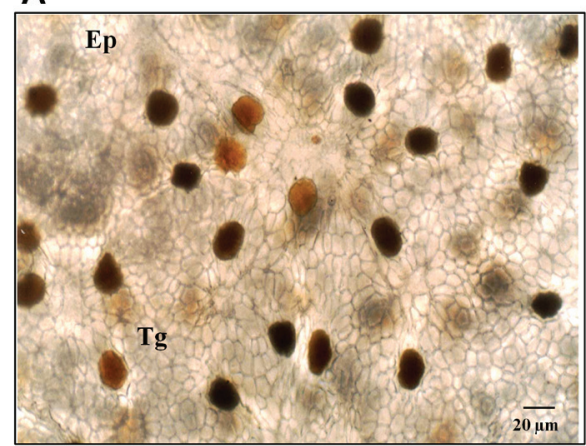

B

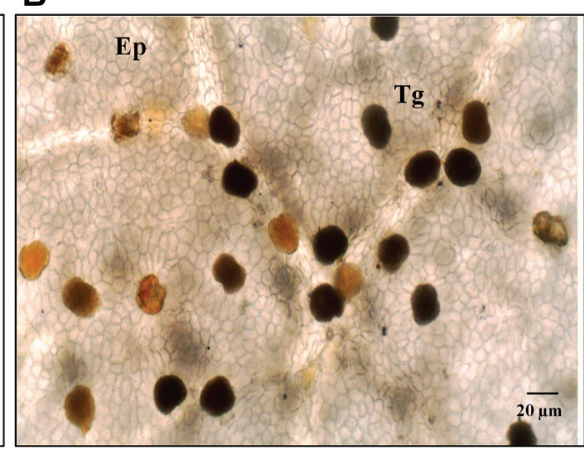

C Folhas jovens

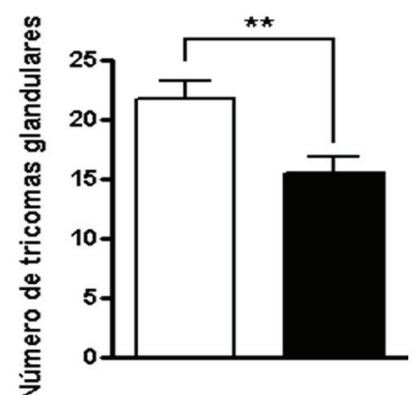

Figura 3 A-C. Quantificação dos tricomas glandulares na face adaxial das folhas jovens e adultas de Eremanthus erythropappus. A. Vista frontal das folhas jovens, evidenciando o número de tricomas glandulares localizados na face adaxial. B. Vista frontal das folhas adultas, evidenciando o número de tricomas glandulares localizados na face adaxial. Tricomas glandulares mais escuros sugerem a oxidação do óleo essencial nas folhas adultas. C. Quantificação comparativa do número de tricomas glandulares localizados na face adaxial das folhas jovens e adultas. Quatro campos microscópicos aleatórios/folha foram obtidos de 15 indivíduos distintos. Os resultados foram expressos como média \pm desvio padrão. Significância estatística foi calculada pelo teste t de Student, ${ }^{* *} p<0,001$. Ep: Epiderme; Tg: Tricoma glandular.

A

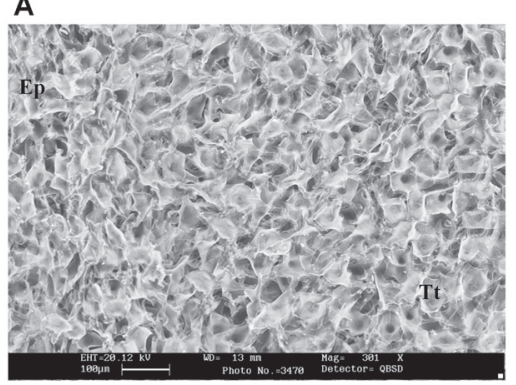

C

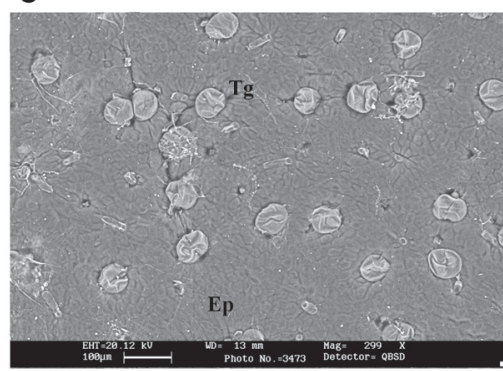

B

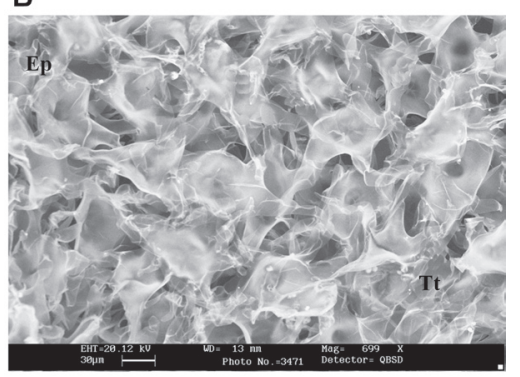

D

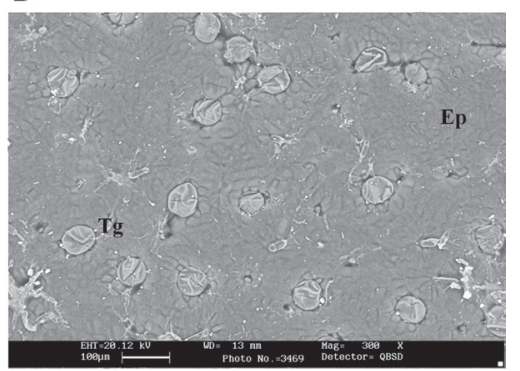

Figura 4 A-D. Análise ultraestrutural das folhas de Eremanthus erythropappus, em microscopia eletrônica de varredura (MEV). A e B. Vista frontal da face abaxial das folhas jovens, evidenciando o grande número de tricomas tectores (A. MEV 300x; B. 700x). C e D. Vista frontal das folhas jovens e adultas, evidenciando um maior número de tricomas glandulares localizados na face adaxial das folhas jovens (C. MEV 300x) quando comparadas com as folhas adultas (D. MEV 300x). Ep: epiderme; Tg: tricoma glandular; Tt: tricoma tector. 


\section{CONCLUSÃO}

A anatomia das folhas de E. erythropappus apresenta estruturas tipicamente xeromorfas, que certamente contribuem para uma proteção mecânica e química foliar para a adaptação desta espécie no seu ambiente natural. A associação de tricomas tectores e glandulares proporciona a proteção das folhas de candeiada-serra a fatores abióticos e bióticos do ambiente, sendo o óleo essencial fundamental devido a sua localização nas duas faces da lâmina foliar. Além disso, em conjunto os resultados do presente trabalho contribuem para a caracterização morfológica e anatômica, assim como para a correta identificação de E. erythropappus.

\section{AGRADECIMENTOS}

Os autores agradecem a Profa. Fátima Regina Gonçalves Salimena Pires pela identificação do material vegetal e ao Laboratório de Patologia, Instituto Oswaldo Cruz/Fiocruz-RJ pela execução da análise ultraestrutural (microscopia eletrônica de varredura-MEV).

\section{REFERÊNCIAS}

Aguilera DB, Meira RMSA, Ferreira FA 2004. Anatomia e histoquímica dos órgãos vegetativos de Siegesbeckia orientalis (Asteraceae). Planta Daninha 22: 483-489.

Baker PM, Fortes CC, Fortes EG, Gazzinelli G, Gilbert B, Lopes JNC, Pellegrino J, Tomassini TCB, Vichnewsky W 1972. Chemoprophylactic agents in shistosomiasis: eremanthine, custonolide, $\alpha$-cyclocostunolide and bisabolol. J Pharm Pharmacol 25: 853-857.

Bohlmann F, Ahmed M, King RM, Robinson H 1981. Labdane and eudesmane derivatives from Ageratum fastigiatum. Phytochemistry 20: 1434-1435.

Braun N, Meier M, Kohlenberg B, Hammerschimidt FJ 2003. Two new bisabolone diols from the stem wood essential oil of Vanillosmopsis erythropappa Schultz-Bip (Asteraceae). J Essent Oil Res 15: 139-142.

Carvalho PER 1994. Espécies florestais brasileiras: recomendações silviculturais, potencialidade e uso da madeira. Embrapa-CNPF: Brasília.

Chaves MMF, Ramalho RS 1996. Estudos morfológicos em sementes, plântulas e mudas de duas espécies arbóreas pioneiras da família Asteraceae (Vanillosmopsis erythropappa Sch. Bip e Vernonia discolor (Spreng.) Less. Rev Arvore 1: 1-7.

Corbrella A, Gariboldi P, Jommi G 1974. Structure and absolute stereochemistry of vanillosmin, a guaianolide from Vanillosmopsis erythropappa. Phytochemitry 13: 459465.

Corrêa MP 1931. Dicionário de plantas úteis do Brasil. Rio de Janeiro: Ministério da Agricultura.

Cruz GL 1995. Dicionário das plantas úteis do Brasil. 5 ed. Rio de Janeiro: Bertrand Brasil.
Del-Vechio-Vieira G, Barbosa MVD, Lopes BC, Sousa OV, Santiago-Fernandes LDR, Esteves RL, Kaplan MAC 2008. Caracterização morfoanatômica de Ageratum fastigiatum (Asteraceae). Rev Bras Farmacogn 18: 769-776.

Ehleringer JR, Mooney HA 1978. Leafhairs: effect on physiological activity and adaptative values to a desert shrub. Oecologia 37: 183-200.

Fahn A 1978. Anatomia vegetal. Madrid: H. Blume.

Fahn A, Cutler D 1992. Xenophytes. Berlim: Gebruder Borntraeger.

Fonseca MCM, Meira RMSA, Casali VWD 2006. Anatomia dos órgãos vegetativos e histolocalização de compostos fenólicos e lipídicos em Porophyllum ruderale (Asteraceae). Planta Daninha 24: 707-713.

Galdino APP 2006. Estudo sobre o rendimento e qualidade do óleo de candeia (Eremanthus ssp.) e a influência das diferentes origens comerciais da sua madeira. Rev Bras Pl Med 8: 44-46.

Gottlieb OR, Kubitzki K 1983. Ecogeographical phytochemistry. A novel approach to the study of plant evolution and disperson. Naturwiss 70: 119-1226.

Gottlieb OR, Magalhães MT 1958. Essential oil of the wood of Vanillosmopsis erythropappa. Perf Essent Oil Rec 49: 711-714.

Gregio SJD, Moscheta IS 2006. Anatomia de raiz, caule e folha e identificação de estruturas secretoras de Achillea millefolium L. (Asteraceae). Acta Biol Acad Sci Hung 28: 327-334.

Harborne JB 1993. Introduction to ecological biochemistry. London: Academic Press, p. 318.

Larcher W 2000. Ecofisiolgia vegetal. São Carlos: RiMa.

Lorenzi H, Matos FJA 2000. Plantas medicinais no Brasil: nativas e exóticas cultivadas. Nova Odessa: Plantarum.

Medri ME, Lleras E 1980. Aspectos da anatomia ecológica de folhas de Hevea brasiliensis Muell. Rev Acta Amazon 10: 463-493.

Metcalfe CR, Chalk L 1950. Anatomy of dicotyledons: leaves, stem, and wood in relation to taxonomy with notes on economic uses. Oxford: Clarendon Press. v. 2.

Morretes BL 1969. Contribuição ao estudo da anatomia das folhas de plantas do cerrado. Bol Fac Filosofia Ciênc Letras USP 24: 7-32.

Mott KA, Gibson AC, O'Leary JW 1982. The adaptative significance of amphistomatic leaves. Plant Cell Environ 5: 455-460.

Oliveira F, Rodrigues RFO, Bastos DHM, Pereira FH 2000. Caracterização morfo-histológica e verificação da atividade microbiológica da espécie vegetal Mikania cordifolia Willd. Lecta 18: 33-63.

Parkhust DF 1978. The adaptative significance of stomatal occurrence on one or both surfaces of leaves. $J$ Ecol 66: 367-383.

Pedralli G, Teixeira MCB, Nunes YR, 1997. Rev Arvore, p. 21301.

Pérez FM 2001. Sistema de manejo para a candeia (Eremanthus 
erythropappus DC McLeish). Minas Gerais, 71p. Dissertação de Mestrado - Programa de Pós-Graduação em Manejo Ambiental, Universidade Federal de Lavras.

Rodrigues RF, Oliveira F, Kato ETM 1996. Morfodiagnose da droga conhecida como cipó-almécega - Mikania malacolepsis Robinson. Rev Farm Bioquim Univ Sao Paulo 32: 37-44.

Roeser KR 1972. Die Nadel der Schwarzkiefer-Massenprodukt und Kunstwerk der Natur. Mikrokosmos 61: 33-36.

Salatino A, Montenegro G, Salatino MLF 1986. Microscopia eletrônica de varredura de superfícies foliares de espécies lenhosas do cerrado. Rev Bras Bot 9: 117-124.

Sass JE 1951. Botanical microtechnique. 2 ed. Ames: Iowa State College, p. 97.

Scolforo JRS, Oliveira AD, Davide AC, Mello JM, Acerbi Júnior FW 2002. Manejo sustentável da candeia Eremanthus erythropappus e Eremanthus incanus. Lavras: UFLA/ FAEPE.

Scolforo JRS 2004. Estimativas de volume, peso seco, peso de óleo e quantificação de moirões para a candeia (Eremanthus erythropappus (DC.) MacLeish). Minas Gerais, 102 p. Dissertação de Mestrado - Programa de Pós-Graduação em Manejo Ambiental, Universidade Federal de Lavras.

Silvério MS 2004. Estudo químico e farmacológico de Vanillosmopsis erythropappa Schultz Bip. (Asteraceae). Rio de Janeiro, 94 p. Dissertação de Mestrado - Programa de Pós-Graduação em Farmacologia e Terapêutica Experimental, Universidade Federal do Rio de Janeiro.

Silvério MS, Sousa OV, Del-Vechio-Vieira G, Miranda MA, Matheus FC, Kaplan MAC 2008. Propriedades farmacológicas do extrato etanólico de Eremanthus erythropappus (DC) McLeisch (Asteraceae). Rev Bras Farmacogn 18: 430-435.

Sousa OV, Dutra RC, Yamamoto CH, Pimenta DP 2008a. Estudo comparativo da composição química e da atividade biológica dos óleos essenciais das folhas de Eremanthus erythropappus (DC) McLeisch. Rev Bras Farm 89: 113-116.

Sousa OV, Oliveira MS, Rabello SV, Cunha RO, Costa BLS, Leite MN 2003. Estudo farmacognóstico dos galhos de Vanillosmopsis erythropappa. Rev Bras Farmacogn 13: 50-53.

Sousa OV, Silvério MS, Del-Vechio-Vieira G, Matheus FC, Yamamoto $\mathrm{CH}$, Alves MS 2008b. Antinociceptive and anti-inflammatory effects of the essential oil from Eremanthus erythropappus leaves. J Pharm Pharmacol 60: 771-7.

Tavares ES, Gil VR, Viana VRC 2000. Anatomia do eixo vegetativo de Ageratum conyzoides L. (Asteraceae). Rev Bras Farm 31: 25-28.

Vichnewski W, Lopes JNC, Santos Filho D, Herz W 1976. 15-Deosygoyazensolide, a new heliangolide from Vanillosmopsis erythropappa. Phytochemistry 15: 1775-1776. 